\title{
A WEAK- $(p, q)$ INEQUALITY FOR FRACTIONAL INTEGRAL OPERATOR ON MORREY SPACES VIA HEDBERG TYPE INEQUALITY
}

\author{
Idha Sihwaningrum \\ Jenderal Soedirman University, Indonesia \\ idha.sihwaningrum@unsoed.ac.id \\ Hendra Gunawan \\ Bandung Institute of Technology, Indonesia \\ hgunawan@math.itb.ac.id
}

\begin{abstract}
$\boldsymbol{A B S T R A C T}$ By employing the growth measure, in this paper we prove the weak- $(p, q)$ inequality for fractional integral operator on Morrey spaces via Hedberg type inequality. The proof also needs the weak- $(p, p)$ inequality of the maximal operator in the same spaces.

Keywords: Fractional integral operator, maximal operator, Morrey spaces, weak inequality.
\end{abstract}

ABSTRAK Dengan menggunakan ukuran growth, pada makalah ini dibuktikan ketaksamaan lemah $(p, q)$ untuk operator integral fraksional pada ruang Morrey via ketaksamaan tipe Hedberg. Bukti ini juga memerlukan ketaksamaan lemah $(p, p)$ dari operator maksimal di ruang yang sama.

Kata Kunci: Operator integral fraksional, operator maksimal, ruang Morrey, ketaksamaan lemah.

\section{INTRODUCTION}

In this paper we prove the weak- $(p, q)$ inequality for fractional integral operator on Morrey spaces, where $1 \leq p<\infty$ and $1 \leq q<\infty$. Fractional integral $I_{\alpha}$, which is also known as the Riesz potential, is defined by

$$
I_{\alpha} f(x):=\int_{X} \frac{f(y)}{d(x, y)^{n-\alpha}} d \mu(y)
$$

(García-Cuerva and Gatto, 2004). In this definition, $X=(X, d, \mu)$ is a metric measure space which is equipped with the metric (distance function) $d$ and Borel measure $\mu$. Particularly, we take the measure to be the growth measure, that is a measure which satisfies the growth condition

$$
\mu(B(x, r)) \leq C r^{n}
$$

for every ball $B(x, r)$ with center $x$ and radius $r$. The orde of the measure, $n$, is less than or equal to the dimension of the metric space. The positive constant $C$ is independent of $x$ and $r$. Here and after, $C$ will be used to denote any positive constant which could be vary from line to line. The works using such measure firstly introduced in (Nazarov, et al., 1998) and (Tolsa, 1998). Meanwhile, Verdera (2002) provided some examples on the use of this measure. Other 
works employing such measure can be found for example in (García-Cuerva and Martell, 2001), (Sihwaningrum, et al., 2012), and (Hakim and Gunawan, 2013).

The fractional integral operator in equation (1) is a development of the fractional integral operator given by (Hardy and Littlewood, 1927). Some results on this operator can be found for example in (Adams, 1975), (Nakai, 1994), (Kurata, et al., 2002) and (Eridani, et al., 2014). Other results on the different version of fractional integral operator can be viewed in (Sawano and Shimamura, 2013) and (Sihwaningrum and Sawano, 2013). Meanwhile, the fractional integral operator (equation (1) has been proved to satisfy the weak- $(1, q)$ inequality (where $1 \leq q<\infty$ ) in Lebesgue spaces (García-Cuerva and Gatto, 2004), in Morrey spaces (Sihwaningrum, 2016a) and in generalized Morrey spaces (Sihwaningrum, et al., 2015). This fractional integral operator also satisfies the weak- $(p, q)$ inequality (where $1 \leq p<\infty$ and $1 \leq q<\infty$ ) in Morrey spaces (Sihwaningrum, 2016b). Morrey spaces were first introduced by Morrey (1940); and in this paper, we defined Morrey spaces $L^{p, \lambda}(\mu):=L^{p, \lambda}(X, \mu)$ (for $1 \leq p<\infty$ and $0 \leq \lambda<n$ ) to be the set of all functions in $L_{\mathrm{loc}}^{p}$ in which

$$
\|f\|_{L^{p, \lambda}(\mu)}^{p}:=\sup _{B(x, r)}\left(\frac{1}{(\mu(B(x, 2 r)))^{\lambda}} \int_{B(x, r)}|f(y)|^{p} d \mu(y)\right)^{1 / p}<\infty .
$$

The weak inequalities, which measure the size of the distribution function (Duoandikoetxea, $2001)$, can be proved with or without Hedberg type inequality. The weak- $(p, q)$ inequality in Morrey spaces given by Sihwaningrum (2016b) is proved without Hedberg type inequality. In this paper, we give an alternative proof of this inequality by employing the Hedberg type inequality. The original Hedberg type inequality is available in (Hedberg, 1972). This alternative proof will also need the weak- $(p, p)$ inequality of operator maximal

$$
M^{p} f(x):=\left(M|f|^{p}(x)\right)^{1 / p}=\sup _{r>0}\left(\frac{\int_{B(x, r)}|f(y)|^{p} d \mu(y)}{\mu(B(x, 2 r))}\right)^{1 / p}
$$

in Morrey spaces. In equation (3), the operator $M$ is defined by Sawano (2005) to be

$$
M f(x):=\sup _{r>0} \frac{1}{\mu(B(x, 2 r))} \int_{B(x, r)}|f(y)| d \mu(y) \quad(x \in \operatorname{supp}(\mu)) .
$$

Also, equation (3) is reduced to equation (4) if $p=1$. Some properties of $M$ are presented in some papers such as (Terasawa, 2006).

\section{Main Results}

The following Hedberg type inequality is an estimate for fractional integral operator $I_{\alpha}$ by the maximal operator $M^{p}$.

Theorem 2.1. Let $0<\alpha<n$ and $1 \leq p \leq q<\infty$. If there is $\lambda$ such that $0 \leq \lambda<1-\frac{\alpha p}{n}$, then we have inequality

$$
\left|I_{\alpha} f(x)\right| \leq C\left(M^{p} f(x)\right)^{1-\frac{\alpha p}{n(1-\lambda)}}\|f\|_{L^{p, \lambda(\mu)}}^{\frac{\alpha p}{n(1-\lambda)}} .
$$

Proof. Let $r>0$ and $x \in X$. For any function $f$ in $L^{p, \lambda}(\mu)$, it is possible for us to decompose the integral in the definition of the fractional integral operator such that

$$
\begin{aligned}
\left|I_{\alpha} f(x)\right| & \leq \int_{B(x, r)} \frac{|f(y)|}{d(x, y)^{n-\alpha}} d \mu(y)+\int_{X \backslash B(x, r)} \frac{|f(y)|}{d(x, y)^{n-\alpha}} d \mu(y) \\
& =A_{1}+A_{2} .
\end{aligned}
$$


By taking into account the growth condition of $\mu$, we find an estimate for $A_{1}$, that is

$$
\begin{aligned}
A_{1} & \leq \sum_{j=-\infty}^{-1} \int_{B\left(x, 2^{j+1} r\right) \backslash B\left(x, 2^{j} r\right)} \frac{|f(y)|}{d(x, y)^{n-\alpha}} d \mu(y) \\
& \leq \sum_{j=-\infty}^{-1} \frac{1}{\left(2^{j} r\right)^{n-\alpha}} \int_{B\left(x, 2^{j+1} r\right)}|f(y)| d \mu(y) \\
& =\sum_{j=-\infty}^{-1} \frac{\left(2^{j} r\right)^{\alpha} 2^{2 n}}{\left(2^{j+2} r\right)^{n}} \int_{B\left(x, 2^{j+1} r\right)}|f(y)| d \mu(y) \\
& \leq C \sum_{j=-\infty}^{-1}\left(2^{j} r\right)^{\alpha}\left(\frac{\int_{B\left(x, 2^{j+1} r\right)}|f(y)|^{p} d \mu(y)}{\mu\left(B\left(x, 2^{j+2} r\right)\right)}\right)^{1 / p}\left(\frac{\int_{B\left(x, 2^{j+1} r\right)} d \mu(y)}{\mu\left(B\left(x, 2^{j+2} r\right)\right)}\right)^{1-1 / p} \\
& \leq C \sum_{j=-\infty}^{-1}\left(2^{j} r\right)^{\alpha} M^{p} f(x)\left(\frac{\mu\left(B\left(x, 2^{j+1} r\right)\right)}{\mu\left(B\left(x, 2^{j+2} r\right)\right)}\right)^{1-1 / p} \\
& \leq C r^{\alpha} M^{p} f(x) .
\end{aligned}
$$

The growth condition of $\mu$ also provides us with

$$
\begin{aligned}
A_{2} & \leq \sum_{j=0}^{\infty} \int_{B\left(x, 2^{j+1} r\right) \backslash B\left(x, 2^{j} r\right)} \frac{|f(y)|}{d(x, y)^{n-\alpha}} d \mu(y) \\
& \leq \sum_{j=0}^{\infty} \frac{1}{\left(2^{j} r\right)^{n-\alpha}} \int_{B\left(x, 2^{j+1} r\right)}|f(y)| d \mu(y) \\
& \leq \sum_{j=0}^{\infty} \frac{\left(2^{j} r\right)^{\alpha}\left(\int_{B\left(x, 2^{j+1} r\right)}|f(y)|^{p} d \mu(y)\right)^{1 / p}\left(\int_{B\left(x, 2^{j+1} r\right)} d \mu(y)\right)^{1-1 / p}}{\mu\left(B\left(x, 2^{j+2} r\right)\right)} \\
& \leq C r^{\alpha} \sum_{j=0}^{\infty} \frac{2^{j \alpha} \mu\left(B\left(x, 2^{j+1} r\right)\right)^{1-1 / p}}{\mu\left(B\left(x, 2^{j+2} r\right)\right)^{1-\lambda / p}}\left(\frac{\int_{B\left(x, 2^{j+1} r\right)}|f(y)|^{p} d \mu(y)}{\mu\left(B\left(x, 2^{j+2} r\right)\right)^{\lambda}}\right)^{1 / p} \\
& \leq C r^{\alpha}\|f\|_{L^{p, \lambda}(\mu)} \sum_{j=0}^{\infty} 2^{j \alpha}\left(2^{j+1} r\right)^{n(1-1 / p)}\left(2^{j+2} r\right)^{n(\lambda / p-1)} \\
& =C r^{\alpha}\|f\|_{L^{p, \lambda}(\mu)} \sum_{j=0}^{\infty} 2^{\alpha+n(\lambda-1) / p} r^{n(\lambda-1) / p} \\
& \leq C r^{\alpha+n(\lambda-1) / p}\|f\|_{L^{p, \lambda}(\mu) .}
\end{aligned}
$$

Now, by letting

the inequality

$$
r:=\left(\frac{M^{p} f(x)}{\|f\|_{L^{p, \lambda}(\mu)}}\right)^{\frac{p}{n(\lambda-1)}}
$$

$$
\left|I_{\alpha} f(x)\right| \leq C\left(M^{p} f(x)\right)^{1-\frac{\alpha p}{n(1-\lambda)}}\|f\|_{L^{p, \lambda(\mu)}}^{\frac{\alpha p}{n(1-\lambda)}}
$$

follows.

As our next result, we have the weak- $(p, p)$ inequality for maximal operator $M^{p}$. The proof of this weak inequality uses Theorem 2.1 presented in (Sihwaningrum, 2016b). 
Theorem 2.2. For $1 \leq p<\infty$, there is a positive constant $C$ such that for every positive $\gamma$ and every ball $B(a, r)$ in $X$, the inequality

$$
\mu\left(\left\{x \in B(a, r): M^{p} f(x)>\gamma\right\}\right) \leq C r^{n \lambda}\left(\frac{\|f\|_{L^{p, \lambda}(\mu)}}{\gamma}\right)^{p}
$$

holds.

Proof. By using Theorem 2.1 in (Sihwaningrum, 2016b), we find that

$$
\begin{aligned}
\mu & \left(\left\{x \in B(a, r): M^{p} f(x)>\gamma\right\}\right) \\
& \leq \int_{\left\{x \in B(a, r): M|f|^{p}(x)>\gamma^{p}\right\}} \chi_{B(a, r)}(x) d \mu(x) \\
& \leq \frac{C}{\gamma^{p}} \int_{X}|f(x)|^{p} M \chi_{B(a, r)}(x) d \mu(x) \\
& \leq C r^{n \lambda}\left(\frac{\|f\|_{L^{p, \lambda}(\mu)}}{\gamma}\right)^{p} .
\end{aligned}
$$

Therefore, our proof is complete.

Now, we state Theorem 2.2 in (Sihwaningrum, 2016b) and present an alternative proof for the theorem, that is by using the Hedberg type inequality (Theorem 2.1).

Theorem 2.3. Let $0<\alpha<n, 1 \leq p \leq q<\infty$, and $0 \leq \lambda<1-\frac{\alpha p}{n}$. If $\frac{1}{q}=\frac{1}{p}-\frac{\alpha}{n(1-\lambda)}$, then

$$
\mu\left(\left\{x \in B(a, r): \mid I_{\alpha} f(x)>\gamma\right\}\right) \leq C r^{n \lambda}\left(\frac{\|f\|_{L^{p, \lambda}(\mu)}}{\gamma}\right)^{q} .
$$

Proof. Since $\frac{1}{q}=\frac{1}{p}-\frac{\alpha}{n(1-\lambda)}=\frac{n(\lambda-1)+\alpha p}{p n(\lambda-1)}$, the Hedberg type inequality gives us

$$
\gamma<\left|I_{\alpha} f(x)\right| \leq C\left(M^{p} f(x)\right)^{p / q}\|f\|_{L^{p, \lambda}(\mu)}^{\frac{\alpha p}{n(1-\lambda)}} .
$$

Furthermore, the weak type $(p, p)$ inequality for maximal operators in Theorem 2.2 allows us to find

$$
\begin{aligned}
\mu(\{x & \left.\left.\in B(a, r):\left|I_{\alpha} f(x)\right|>\gamma\right\}\right) \\
& \leq \mu\left(\left\{x \in B(a, r): M^{p} f(x)>\left(\frac{\gamma}{\|f\|_{L^{p, \lambda}(\mu)}^{\frac{\alpha p}{n(1-\lambda)}}}\right)^{q / p}\right\}\right) \\
& \leq C r^{n \lambda}\|f\|_{L^{p, \lambda}(\mu)}^{p}\left(\frac{\|f\|_{L^{p, \lambda}(\mu)}^{\frac{\alpha p}{n(1-\lambda)}}}{\gamma}\right)^{q} \\
& =C r^{n \lambda}\left(\frac{\|f\|^{\frac{p(n(\lambda-1)+\alpha p)}{p n(\lambda-1)}}\|f\|_{L^{p, \lambda}(\mu)}^{\frac{\alpha p}{n(1-\lambda)}}}{\gamma}\right)^{q} \\
& =C r^{n \lambda}\left(\frac{\|f\|_{L^{p, \lambda}(\mu)}}{\gamma}\right)^{q} .
\end{aligned}
$$

This is the desired inequality. 


\section{Concluding Remarks}

In this paper we use Hedberg type inequality, which is a common method to prove a weak type inequality. If we take $p=1$, our result is reduced to the result in (Sihwaningrum, 2016a). Furthermore, when we take the metric spaces to be the Euclidean spaces, Hakim and Gunawan (2013) found that the fractional integral operator satisfies the weak- $(p, q)$ inequality on the generalized Morrey spaces. Hence, our result is possible to extend into generalized Morrey spaces over metric measure spaces.

Acknowledgments. This paper is a result of Fundamental Research Program 2015, Directorate General of Higher Education, Indonesia, No. 2101/UN23.14/PN/2015.

\section{References}

Adams, D., A Note on Riesz Potentials, Duke Math. J., 42 (1975), 765-778.

Duoandikoetxea, J., Fourier Analysis, The American Mathematical Society, USA, 2001, 28.

Eridani, Gunawan, H., Nakai, E., and Sawano, Y., Characterization for the Generalized Fractional Integral Operators on Morrey Spaces, J. Math. Inequal. Appl., 17(2) (2014), 761-777

García-Cuerva, J. and Gatto, A.E., Boundedness Properties of Fractional Integral Operators Associated to Non-doubling Measures, Studia Math., 162 (2004), 245-261.

García-Cuerva, J. and Martell, J.M., Two Weight Norm Inequalities for Maximal Operators and Fractional Integrals on Non-homogeneous Spaces, Indiana Univ. Math. J., 50 (2001), 1241-1280.

Hakim, D.I. and Gunawan, H., Weak $(p, q)$ Inequalities for Fractional Integral Operators on Generalized Morrey Spaces of Non-homogeneous Type, Math. Aeterna, 3(3) (2013), 161-168.

Hardy, G.H. and Littlewood, J. E., Some Properties of Fractional Integrals I, Math. Zeit., 27 (1927), 565-606.

Hedberg, L.I., On Certain Convolution Inequalities, Proc. Amer. Math. Soc., 36 (1972), 505510 .

Kurata, K., Nishigaki, S., and Sugano, S., Boundedness of Integral Operators on Generalized Morrey Spaces and Its Application to Schrödinger Operators, Proc. Amer. Math. Soc., 128 (2002), 1125-1134.

Nazarov, F., Treil, S., and Volberg, A., Weak Type Estimates and Cotlar Inequalities for Calderón-Zygmund Operators on Nonhomogeneous Spaces, Internat. Math. Res. Notices, 9 (1998), 463-487.

Morrey, C.B., Functions of Several Variables and Absolute Continuity, Duke Math. J., 6 (1940), $187-215$.

Nakai, E., Hardy-Littlewood Maximal Operator, Singular Integral Operators, and the Riesz Potentials on Generalized Morrey Spaces, Math. Nachr., 166 (1994), 95-103. 
Sawano, Y., Sharp Estimates of the Modified Hardy-Littlewood Maximal Operator on the Nonhomogeneous Space via Covering Lemmas, Hokkaido Math. J., 34 (2005), 435-458.

Sawano, Y. and Shimomura,T., Sobolev's Inequality for Riesz Potentials of Functions in Generalized Morrey Spaces with Variable Exponent Attaining the Value 1 over Non-doubling Measure Spaces, J. Inequal. Appl., 2013 (2013), 1-19.

Sihwaningrum, I., Ketaksamaan Tipe Lemah untuk Operator Integral Fraksional di Ruang Morrey atas Ruang Metrik Tak Homogen, Prosiding Konferensi Nasional Penelitian Matematika dan Pembelajarannya (KNPMP I), Universitas Muhammadiyah Surakarta, 2016a, 924-933

Sihwaningrum, I., A weak- $(p, q)$ Inequality for Fractional Integral Operator on Morrey Spaces over Metric Measure Spaces, Jurnal Ilmiah Matematika dan Pendidikan Matematika, 8(1) (2016b), 1-7.

Sihwaningrum, I., Maryani, S., and Gunawan, H., Weak Type Inequalities for Fractional Integral Operators on Generalized Non-homogeneous Morrey Spaces, Anal. Theory Appl., 28(1) (2012), 65-72.

Sihwaningrum and Sawano,Y., Weak and Strong Type Estimates for Fractional Integral Operator on Morrey Spaces over Metric Measure Spaces, Eurasian Math. J., 4 (2013), 76-81.

Sihwaningrum, I., Wardayani, A., and Gunawan, H., Weak Type Inequalities for Some Operators on Generalized Morrey Spaces Over Metric Measure Spaces, Austral. J. Math. Anal. Appl., 12 (2015), Issue 1, Art. 16, 9 pp.

Terasawa, Y., Outer Measure and Weak Type $(1,1)$ Estimates of Hardy-Littlewood Maximal Operators, J. Inequal. and Appl., 2016 (2016), Article ID 15063, 13pp

Tolsa, X., Cotlar Inequality without the Doubling Condition and Existence of Principal Values the Cauchy Integral of Measures, J. Reine Angew. Math., 502 (1998), 199-292.

Verdera, J., The Fall of the Doubling Conditions in Calderón-Zygmund Theory, Publ. Mat., Vol. Extra (2002), 275-292. 